\title{
Provision of Gefitinib as Targeted Therapy in Lung Adenocarcinoma with EGFR Mutation and Brain Metastatic
}

\author{
Komang Sri Rahayu Widiasari*1, Yani Jane Sugiri', Farhad Bal'afif ${ }^{2}$, Imam Sarwono ${ }^{3}$ \\ ${ }^{1}$ Pulmonology and Respiratory Department, Saiful Anwar Hospital, Brawijaya University, Jaksa Agung Suprapto 2, Malang, 65112, Indonesia \\ ${ }^{2}$ Neurosurgery Department, Saiful Anwar Hospital, Brawijaya University, Jaksa Agung Suprapto 2, Malang, 65112, Indonesia \\ ${ }^{3}$ Pathology Department, Saiful Anwar Hospital, Brawijaya University, Jaksa Agung Suprapto 2, Malang, 65112, Indonesia
}

\begin{abstract}
Adenocarcinoma is a malignant epithelial tumor with glandular differentiation or mucin production. Adenocarcinoma covers $30 \%$ of lung cancers in Europe and America. This report described a case of an unusual chronic headache since 3 years ago without any complementing symptom except for nausea. The primary tumor was detected with Thorax CT scan and confirmed by histopathology examination. Patient treated with gefitinib $(1 \times 250 \mathrm{mg})$ and showed a satisfying result. Gefitinib, as first-line therapy for patients with epidermal growth factor receptor ( EGFR) mutation, was effective and well-tolerated in this patient.
\end{abstract}

Keywords: adenocarcinoma; lung cancer, chronic headache; EGFR; gefitinib

MRJ 2019; 1(1):11-16

\section{Introduction}

Lung cancer in the broadest sense is all diseases of malignancy in the lungs, these include malignancies arising from the lungs themselves (primary tumor) and the outside (secondary or metastatic tumor in the lungs). Lung cancer is a worldwide issue now and the occurrence of lung cancer is growing ${ }^{1}$. Around 1.2 million people die of lung cancer every year. According to the American Cancer Society, about 160.000 deaths from lung cancers occurred in 2019. This number eclipse the mortality rate caused by colorectal cancer, breast cancer, and prostate cancer which is 125.000 deaths. Of all lung cancers, $35-40 \%$ are adenocarcinomas, $20-30 \%$ are squamous cell carcinomas, $10 \%$ are large cell carcinomas and $15-20 \%$ are small cell ${ }^{*}$ Corresponding author: Komang Sri Rahayu Widiasari (widia.hayu@gmail.com) Pulmonology \& Respiratory Dept, Saiful Anwar Hospital-Brawijaya University, Jaksa Agung Suprapto 2, Malang, 65112, Indonesi mrj.ub.ac.id carcinomas $^{2}$. It is estimated that of 33\% patients with non small cell lung carcinoma (NSCLC) will experience metastasis to the brain throughout the course of their illness ${ }^{3}$.

Carcinogens in the cigarette represent a major role in the incidence of lung cancer. About $85-$ $90 \%$ of lung cancers patients are smokers. But, it also occurs to patients who have never smoked. Host factors also affect individual susceptibility to smoking effects, because only one out of ten smokers in their lifetime will suffer from lung cancers $^{2,4}$.

\section{Case}

A 45-year-old Indonesian woman was admitted due to worsening of chronic intermittent headache alongside with nausea. Vol 01 (1) page 11 
Pain notably on the left side with a characteristic of pulling-like sensation since 3 years ago. She denied having a cough, shortness of breath, fever, chest pain, change of appetite and body weight, night sweats, vomit, and seizure. In 2010, she was admitted to Wava Hospital for 3 days because of hemoptysis. Radiology examination, acid-fast staining, and sputum culture were performed but she wasn't able to recall any specific information. At the same time, she was referred to Saiful Anwar General Hospital for Fiber Optic Bronchoscopy examination. The result was within normal limit and she was diagnosed with fungal infection and treated with intravenous fluconazole. Six days before admission, she went to a neurologist for consultation and underwent head CT (Result: resembling epidural hemorrhage over the left parietal lobe). The patient underwent MRI revealed a meningioma over the left parieto-occipital lobe and referred Saiful Anwar General Hospital for neurosurgery. Further questioning revealed that her aunt had been diagnosed with myoma and ovarian cancer and her nephew with breast fibroadenoma. No history of smoking or environmental tobacco smoking was noted. Significant physical findings only moderately ill patient and slightly overweight woman
(BMI: $27.96 \mathrm{~kg} / \mathrm{m}^{2}$ ). None of the laboratory examinations was significant. Tumor marker result on April 9 ${ }^{\text {th }}$, 2013, was within normal limit. Breast, abdominal, and thyroid ultrasonography was within normal limit. Initial Head CT on March 26 ${ }^{\text {th }}, 2013$, revealed a biconvex hyperdense area over the left parietal lobe with a size of $38 \times 17 \times 32 \mathrm{~mm}$, suggestive of an epidural hematoma. Further characterization with an MRI scan described a Space Occupying Process over the left parietal lobe, suggestive of meningioma (Fig 1).

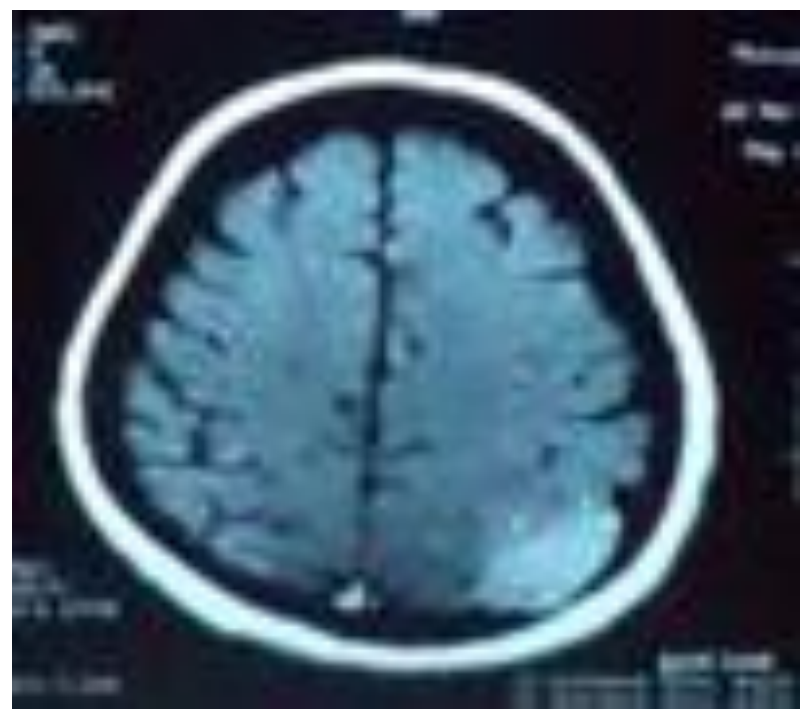

Figure 1. Brain MRI before operation. Brain MRI with and without contrast of Axial T1/T2 WI, T2 Flair, coronal dan sagittal $\mathrm{T} 1 / \mathrm{T} 2$ intracranial revealed a isointense lesion (T1, T2, T2 Flair) in left parietal cortical, which with the addition of contrast showed an increased intensity, firmer boundaries, homogeneous structure, no pathological hyperintense or hypointense lesion. 


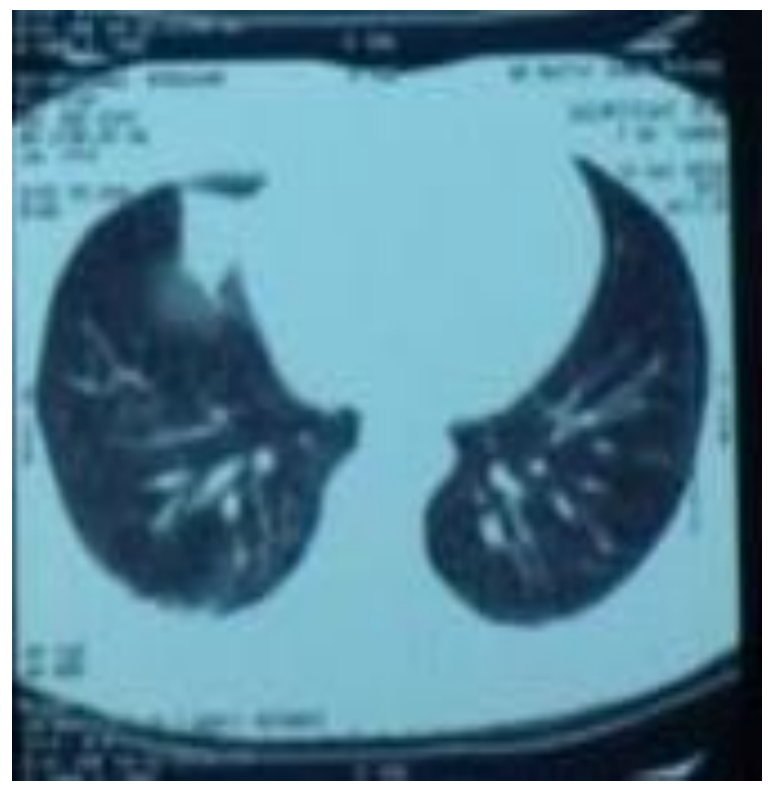

$2 \mathrm{~A}$

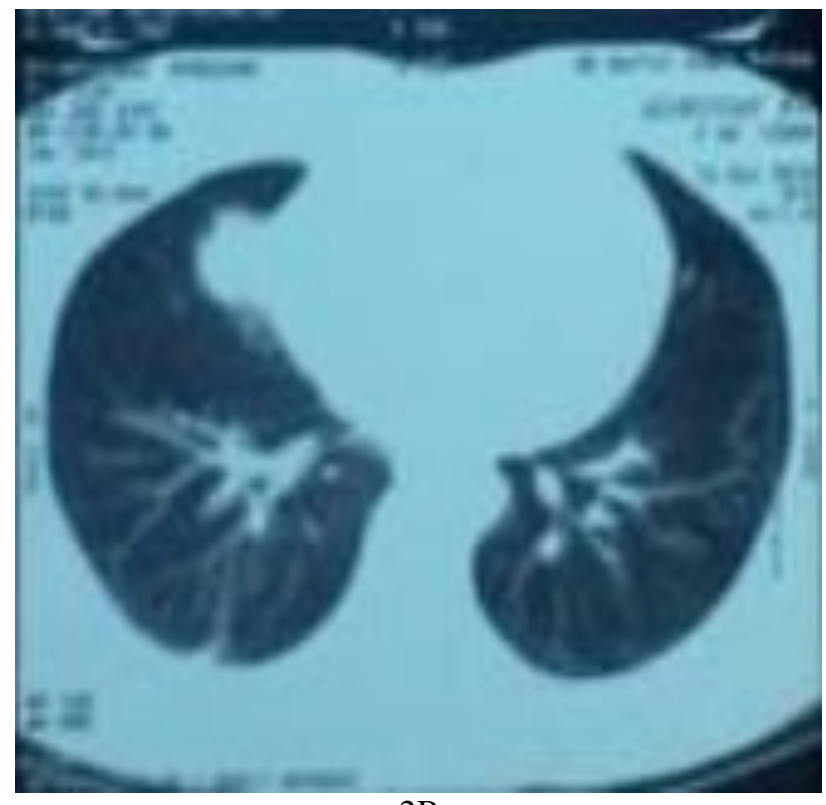

2B

Figure 2A and 2B. Lung CT before chemotherapy. Lung CT showed consolidation with irregular borders which enhanced by contrast administration at 5th right lung segment with size of $20 \times 20 \times 18 \mathrm{~mm}$. Also note the right paratracheal lymphadenopathy and hyperdense area with fluid density at the right lung.

Initial chest radiograph on March $30^{\text {th }}$, 2013, was within normal limit (this was obtained before operation procedure). Chest CT scan was also performed and revealed a solitary nodule with size of $20 \times 20 \times 18 \mathrm{~mm}$ over the right lung and pleural effusion (Fig 2). Another chest radiograph was performed 1 day after the procedure and revealed a right upper lobe infiltrate and right lower lobe nodular infiltrate suggestive of pneumonia. Follow-up chest radiograph ten days after the procedure showed nodular infiltrate with fibrosis over the anterior area of right lower lobe suggestive of metastatic process. Fiber Optic Bronchoscopy (FOB) and spirometry examination were within normal limit. Additional FOB cytology brushing washing showed a malignant cells of class V adenocarcinoma (Fig 4). Molecular analysis was performed on May $14^{\text {th }}, 2013$, and revealed an epidermal growth factor receptor (EGFR) exon 19 deletion mutations.

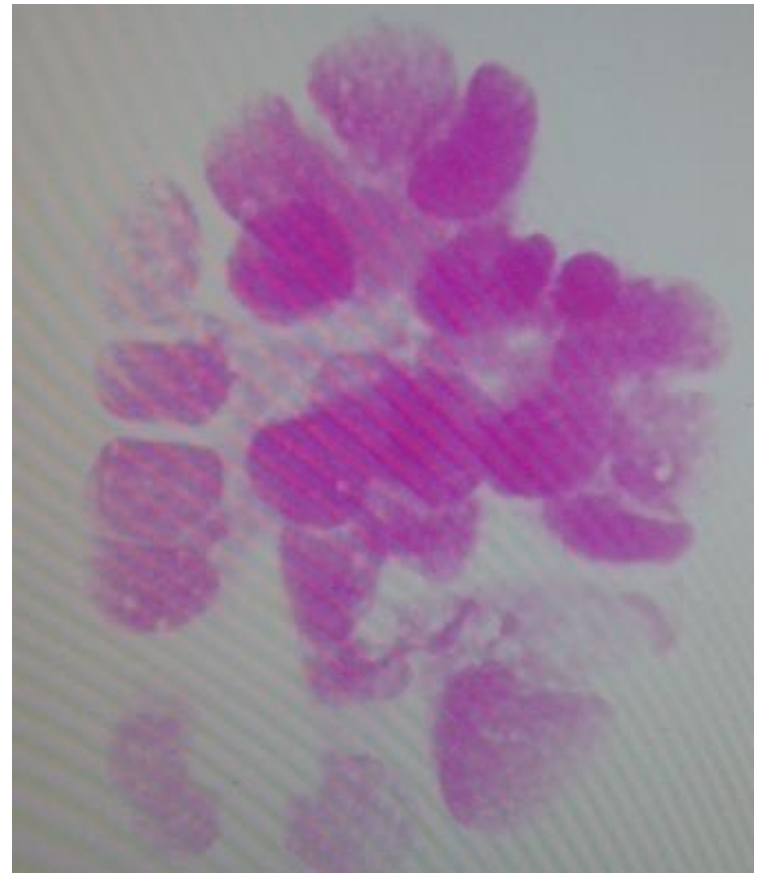

Figure 4. Cytology washing and brushing from Bronchoscopy revealed adenocarcinoma 


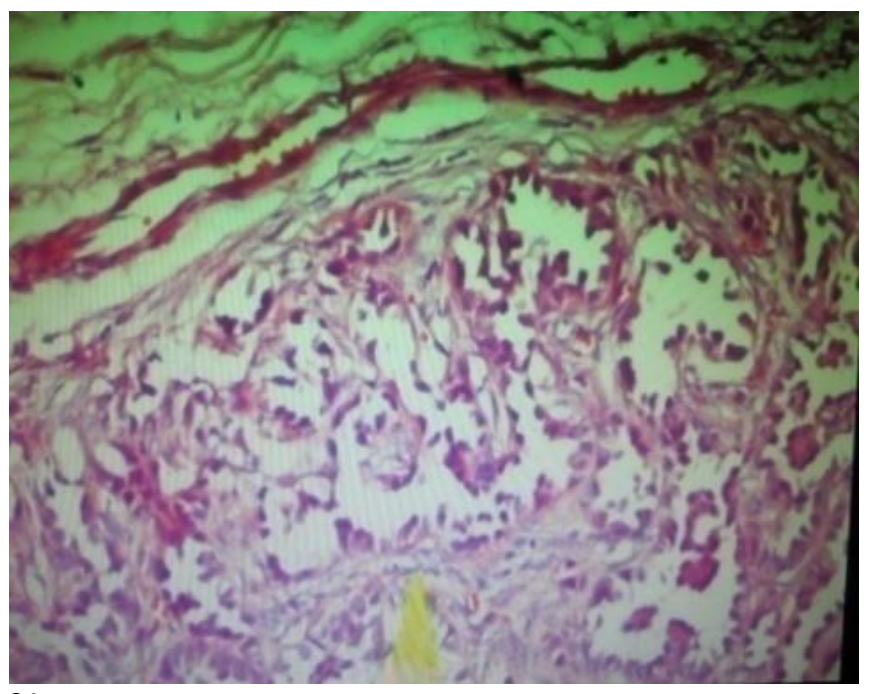

$3 A$

Figures 3A dan 3B. Histopathology examination of extradural and skull after trepanation procedure. Microscopic examination

revealed tumor growth consisting of anaplastic epithelial cell proliferation, round nuclear, pleiomorphic, hyperchromatic, densely arranged resembling a papillary structure, tumor grow to the bone.

To further investigate this finding, a cytologic examination was performed after trepanation procedure and revealed a metastatic papillary adenocarcinoma (Fig 3A and 3B). We initiated therapy on May $27^{\text {th }}$, 2013, with gefitinib $1 \times 250 \mathrm{mg}$ for 2 months and were effective. After two months of therapy, she didn't experience headache, shortness of breath, and cough. She started to work again and live as usual. Her body weight increased by four kilograms (from 60 kilograms to 64 kilograms). After 2 months of therapy. Radiography examination revealed a decrease in tumor size from $20 \mathrm{x}$ $20 \times 18 \mathrm{~mm}$ to $20 \times 18 \times 15 \mathrm{~mm}$ (Fig 5) Classify as Stable Disease as RECIST guideline version 1.1. CEA level was also

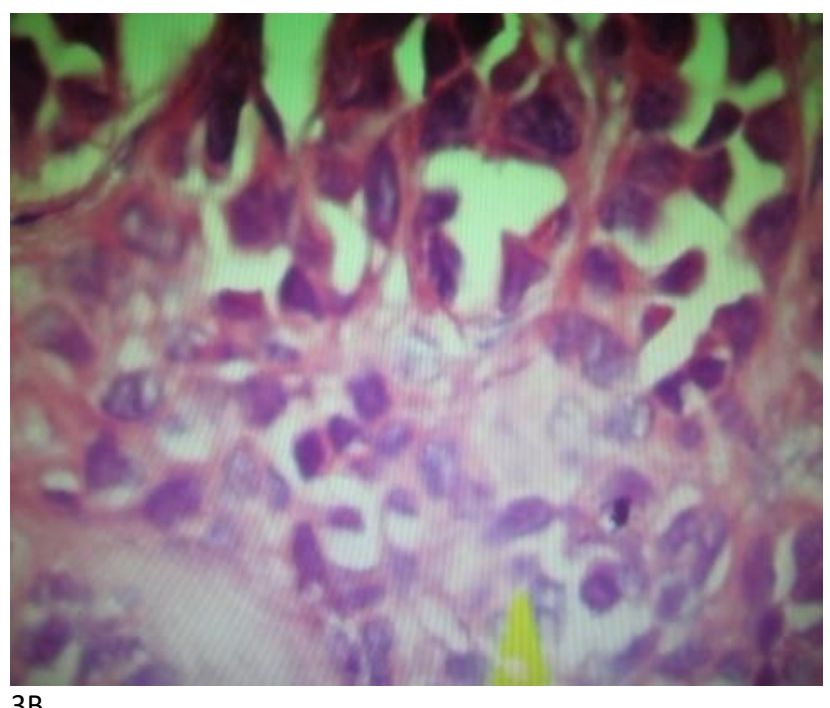

3B

decreased from $10.60 \mathrm{ng} / \mathrm{mL}$ to $1.12 \mathrm{ng} / \mathrm{mL}$ after 6 months of therapy. There weren't any side effects during treatment.

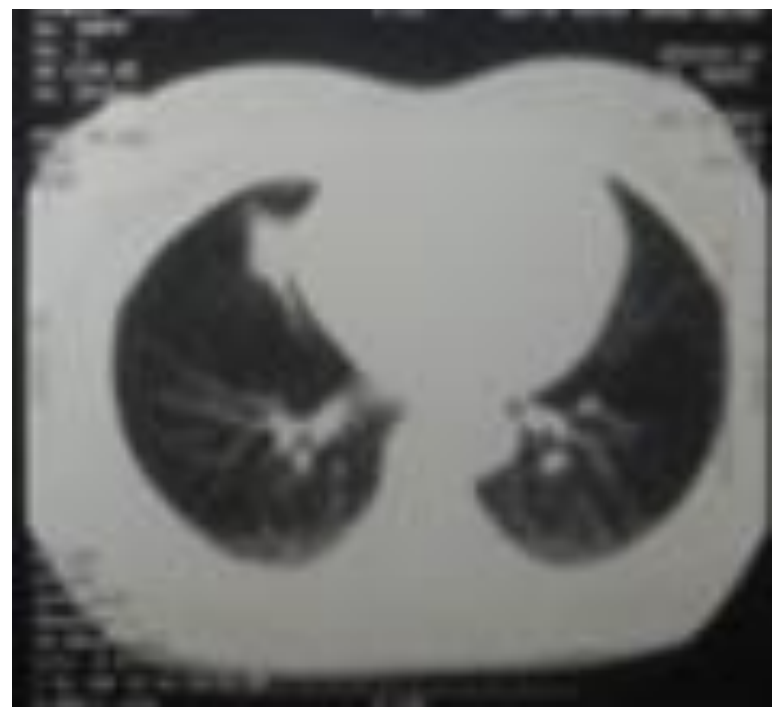

Figure 5. Lung CT after 2 month therapy with gefitinib 1 x 250mg. Lung CT showed an isodense mass with irregular borders, which enhanced by contrast administration at $5^{\text {th }}$ right lung segment with size of $20 \times 18 \times 15 \mathrm{~mm}$. 


\section{Discussion}

Here we present a 41-year-old nonsmoker woman diagnosed with right bronchogenic carcinoma T1aN1M1b and EGFR exon 19 deletion mutations. Histologic examination revealed an adenocarcinoma type of lung cancer. Our patient had a bad prognosis according to NCCN guidelines with 5-year survival rate of $10 \%$. However, NSCLC patients (adenocarcinoma type) with EGFR mutation has better response toward erlotinib or gefitinib regimen. A retrospective study showed an approximately 80\% response rate with median progression-free survival (PFS) 13 months in patient with adenocarcinoma and EGFR mutation who underwent single agent chemotherapy ${ }^{4,5}$.

Our patient's chief complaint was chronic headache since 3 years ago. A literature review state that metastatic cancer has a similar symptom with primary brain tumor. This includes headache, nausea and vomiting, vertigo. Systemic symptoms may occur include decrease in appetite and body weight ${ }^{3}$. Brain metastatic originating from tumors outside the central nervous system are very common. It is estimated that there are 75.000 to 100.000 cases of brain metastatic each year in the United States and 30-60\% of them are primarily lung tumor. When brain metastasis was discovered, cancer had spread widely. About 7\% of patients with neurological symptoms show the presence of solitary brain metastases from lung cancer ${ }^{3,6}$. CEA level is $10,60 \mathrm{ng} / \mathrm{mL}$ (normal : $<5.0 \mathrm{ng} / \mathrm{mL}$ ) and will be used as a monitoring variable for patient's response toward chemotherapy and not for diagnostic purpose. CA-125 level is elevated at 69, 48 $\mathrm{ng} / \mathrm{mL}$ (normal: $<35 \mathrm{U} / \mathrm{mL}$ ). CA-125 is an ovarian cancer marker however, we didn't find any abnormalities on further examination. Molecular analysis is positive for EGFR exon 19 deletion mutations and according to NSCLC NCCN 2013, the firstline regimen should be erlotinib/gefitinib ${ }^{4,7}$. EGFR mutations occur more frequently in Asian races, women, non-smokers, and adenocarcinoma type NSCLC. Epidermal growth factor receptor tyrosine kinase inhibitors (EGFR TKI), such as gefitinib and erlotinib, show a significantly higher response rate (RR) and progression-free survival (PFS) which is significantly longer than standard platinum chemotherapy when given as first line therapy NSCLC patients with EGFR mutations ${ }^{8}$.

Our patient received targeted therapy gefitinib 1 x $250 \mathrm{mg}$. Gefitinib is welltolerated in most patient for long term 
therapy $^{9,10}$. After 6 months of therapy, our patient denies any side effects and she continues her job as a midwife. Along the course of treatment, tumor size and CEA level decreased at 2 months and 6 months, respectively

\section{Conclusion}

This is a case report of a patient with right bronchogenic carcinoma T1aN1M1b and EGFR exon 19 deletion mutations with histologic patterns of adenocarcinoma. Apart from smoking, gene mutations have also been implied as a strong risk factor for lung cancer, especially in patients with EGFR gene mutation, which has been described to be distinctive from those with a smoking history. This mutation warrant provision of erlotinib/gefitinib regimen as first-line therapy. Importantly, gefitinib regimen also safe as we don't find any side effects during 6 months therapy.

\section{References}

1. Perhimpunan Dokter Paru Indonesia. Kanker Paru jenis Karsinoma Bukan Sel Kecil. Pedoman Diagnosis \& Penatalaksanaan di Indonesia. 2011. p.433.

2. Haugen A., Mollerup S. Etiology of Lung cancer . Textbook of Lung Cancer. Second edition. United Kingdom : Informa Healthcare; 2008, p.1-9.
3. Berger, S. Mitchel, Prados D. Michael.Brain Metastasis from Non-Small Cell Lung Cancer. Textbook of NeuroOncology, Pennsylvania : Elsevier Inc; 2005. p.391-398.

4. National Comprehensive Care Network (NCCN). Non Small Cell Lung Cancer. 2013, p.30-97.

5. Kuwata T, Yoneda K, Kobayashi K, Oyama R, Matumiya H, Shinohara S et al. Achievement of Cure with Gefitinib in Advanced Lung Adenocarcinoma Harboring an Activating EGFR Mutation: A Case Report. Case Reports in Oncology. 2016;9(3):565-567.

6. Cho S, Park L, Ji J, Park S, Hwang D, Lee J et al. Efficacy of EGFR tyrosine kinase inhibitors for non-adenocarcinoma NSCLC patients with EGFR mutation. Cancer Chemotherapy and Pharmacology. 2012;70(2):315-320.

7. Bonnette P, Puyo P, Gabriel C, Giudicelli $\mathrm{R}$, Regnard J, Riquet $\mathrm{M}$ et al. Surgical Management of Non-small Cell Lung Cancer With Synchronous Brain Metastases. Chest. 2001;119(5):1469-1475.

8. Nurwidya F, Takahashi F, Takahashi K. Gefitinib in the treatment of nonsmall cell lung cancer with activating epidermal growth factor receptor mutation. Journal of Natural Science, Biology and Medicine. 2016;7(2):119.

9. Hirsch F, Sequist L, Gore I, Mooradian M, Simon G, Croft E et al. Long-term safety and survival with gefitinib in select patients with advanced non-small cell lung cancer: Results from the US IRESSA Clinical Access Program (ICAP). Cancer. 2018;124(11):2407-2414.

10. Sim E, Yang I, Wood-Baker R, Bowman R, Fong K. Gefitinib for advanced non-small cell lung cancer. Cochrane Database of Systematic Reviews. 2018. 